\title{
A DIGNIDADE DA PESSOA HUMANA COMO VALOR SUPREMO DA DEMOCRACIA
}

\author{
José AFONSO DA Silva*
}

1. Fundamento constitucional - 2. Pessoa humana - 3. Dignidade 4. Proteção constitucional da dignidade humana - 5. Natureza da dignidade tutelada - 6. Conclusão

\section{Fundamento constitucional}

Foi a Lei Fundamental da República Federal da Alemanha que, por primeiro, erigiu a dignidade da pessoa humana em direito fundamental expressamente estabelecido no seu art. 1, $\mathrm{n}^{\mathfrak{Q}} 1$, declarando: "A dignidade humana é inviolável. Respeitá-la e protegêe-la é obrigação de todos os Poderes estatais".' Fundamentou a positivação constitucional desse princípio, de base filosófica, o fato de o Estado nazista ter vulnerado gravemente a dignidade da pessoa humana mediante a prática de horrorosos crimes políticos sob a invocação de razões de Estado e outras razões. ${ }^{2}$ Os mesmos motivos históricos justificaram a declaração do art. $1^{2}$ da Constituição Portuguesa segundo o qual "Portugal é uma República soberana, baseada na dignidade da pessoa humana e na vontade popular e empenhada na construção de uma sociedade livre, justa e solidária" e também a Constituição espanhola, cujo art. 10, $\mathrm{n}^{\mathbb{1}}$, estatui que "A dignidade da pessoa, os direitos invioláveis que lhe são inerentes, o livre desenvolvimento da personalidade, o respeito à lei e aos direitos dos demais são fundamentos da ordem política e da paz social". E assim também a tortura e toda sorte de desrespeito à pessoa humana praticadas sob o regime militar levaram o Constituinte brasileiro a incluir a dignidade da pessoa humana como um dos

1 “Die Würde des Menschen ist unantastbar. Sie zu achten und zu schützen ist Verpflichtung aller staatlichen Gewalt".

2 Cf. Hans D. Jarass e Bodo Pieroth, Grundgesetz für die Bundesrepublik Deutschland - Kommentar, Münchgen, C. H. Beck'sche Velangsbuchhandlung, 1992, p. 27.

* Professor Titular, aposentado, da Faculdade de Direito da Universidade de São Paulo.

R. Dir. Adm.,

Rio de Janeiro, 212: 89-94, abr./jun. 1998 
fundamentos do Estado Democrático de Direito em que se constitui a República Federativa do Brasil, conforme o disposto no inc. III do art. $1^{2}$ da Constituição de 1988.

A norma compreende dois conceito fundamentais, porque, em si e isoladamente, revelam valores jurídicos: a pessoa humana e a dignidade.

\section{Pessoa humana}

A filosofia kantiana mostra que o homem, como ser racional, existe como fim em si, e não simplesmente como meio, enquanto os seres, desprovidos de razão, têm um valor relativo e condicionado, o de meios, eis por que se lhes chamam coisas ${ }^{3}$ " ao contrário, os seres racionais são chamados de pessoas, porque sua natureza já os designa como fim em si, ou seja, como algo que não pode ser empregado simplesmente como meio e que, por conseguinte, limita na mesma proporção o nosso arbítrio, por ser um objeto de respeito". ${ }^{4} \mathrm{E}$ assim se revela como um valor absoluto, porque a natureza racional existe como fim em si mesma. Assim, o homem se representa necessariamente sua própria existência. Mas qualquer outro ser racional se representa igualmente assim sua existência, em consequiência do mesmo princípio racional que vale também para mim, é, pois, ao mesmo tempo, um princípio objetivo que vale para outra pessoa. Daí o imperativo prático, posto por Kant: "Age de tal sorte que consideres a humanidade, tanto na tua pessoa como na pessoa de qualquer outro, sempre e simultaneamente como fim e nunca simplesmente como meio". Disso decorre que os "seres racionais estão submetidos à lei segundo a qual cada um deles jamais se trate a si mesmo ou aos outros simplesmente como meio, mas sempre e simultaneamente como fins em si". "Isso porque "o homem não é uma coisa, não é, por consequiência, um objeto que possa ser tratado simplesmente como meio, mas deve em todas as suas ações ser sempre considerado como um fim em si”?

Isso, em suma, quer dizer que só o ser humano, o ser racional, é pessoa. Todo ser humano, sem distinção, é pessoa, ou seja, um ser espiritual, que é, ao mesmo tempo, fonte e imputação de todos os valores. Consciência e vivência de si próprio, todo ser humano se reproduz no outro como seu correspondente e reflexo de sua espiritualidade, razão por que desconsiderar uma pessoa significa em última análise desconsiderar a si próprio. Por isso é que a pessoa é um centro de imputação jurídica, porque o Direito existe em função dela e para propiciar seu desenvolvi-

3 Cf. Emmanuel Kant, Fondements de la Métaphysique des Moeur, Paris, Librairie Philosophique J. Vrin, 1992, p. 104, trad. de Victor Delbos.

4 Idem ibidem.

5 Idem ibidem, p. 105.

6 Idem ibidem, p. 111.

7 Idem ibidem, p. 106. 
mento. Nisso já se manifesta a idéia de dignidade de um ser racional que não obedece a outra lei senão àquela que ele mesmo, ao mesmo tempo, institui, no dizer de Kant. ${ }^{8}$

\section{Dignidade}

Voltemos, assim, à filosofia de Kant, segundo a qual no reino dos fins tudo tem um preço ou uma dignidade. Aquilo que tem um preço pode muito bem ser substituído por qualquer outra coisa equivalente. Daí a idéia de valor relativo, de valor condicionado, porque existe simplesmente como meio, o que se relaciona com as inclinações e necessidades geral do homem e tem um preço de mercado, enquanto aquilo que não é um valor relativo, e é superior a qualquer preço, é um valor interno e nāo admite substituto equivalente, é uma dignidade, é o que tem uma dignidade. ${ }^{9}$

Correlacionados assim os conceitos, vê-se que a dignidade é atributo intrínseco, da essência, da pessoa humana, único ser que compreende um valor interno, superior a qualquer preço, que não admite substituição equivalente. Assim a dignidade entranha e se confunde com a própria natureza do ser humano.

\section{Proteção constitucional da dignidade humana}

Portanto, a dignidade da pessoa humana não é uma criação constitucional, pois ela é um desse conceitos a priori, um dado preexistente a toda experiência especulativa, tal como a própria pessoa humana. A Constituição, reconhecendo a sua existência e a sua eminência, transformou-a num valor supremo da ordem jurídica, quando a declara como um dos fundamentos da República Federativa do Brasil constituída em Estado Democrático de Direito.

Não é o caso aqui de empreender uma discussão em torno da distinção entre valores supremos, fundamentos, princípios constitucionais, princípios fundamentais, princípios inspiradores da ordem jurídica e princípios gerais do direito, a fim de buscar um enquadramento da dignidade da pessoa humana num deles. ${ }^{10}$ Apenas convém esclarecer que não se trata de um princípio constitucional fundamental. $\mathrm{E}$ fazemos esse esclarecimento, porque, a partir da promulgação da Constituição de 1988, a doutrina passou a tentar enquadrar tudo nesse conceito, sem atinar que ele é um conceito que se refere apenas à estruturação do ordenamento constitucional, portanto mais limitado do que os princípios constitucionais gerais, que envolvem toda a ordenação jurídica.

8 Idem ibidem, p. 112.

9 Idem ibidem, pp. 112 e 113.

10 Sobre essa discussāo, cf. Jesús González Péres. La Dignidad de la Persoan, Madrid, Civitas, 1986, pp. 82 e ss. 
Poderíamos até dizer que a eminência da dignidade da pessoa humana é tal que é dotada ao mesmo tempo da natureza de valor supremo, princípio constitucional fundamental e geral que inspiram a ordem jurídica. Mas a verdade é que a Constituição lhe dá mais do que isso, quando a põe como fundamento da República Federativa do Brasil constituída em Estado Democrático de Direito. Se é fundamento é porque se constitui num valor supremo, num valor fundante da República, da Federação, do País, da Democracia e do Direito. Portanto, não é apenas um princípio da ordem jurídica, mas o é também da ordem política, social, econômica e cultural. Daí sua natureza de valor supremo, porque está na base de toda a vida nacional.

Repetiremos aqui o que já escrevemos de outra feita, ou seja, que a dignidade da pessoa humana é um valor supremo que atrai o conteúdo de todos os direitos fundamentais do homem, desde o direito à vida. "Concebido como referência constitucional unificadora de todos os direitos fundamentais, observam Gomes Canotilho e Vital Moreira, o conceito de dignidade da pessoa humana obriga a uma densificação valorativa que tenha em conta o seu amplo sentido normativo-constitucional e não uma qualquer idéia apriorística do homem, não podendo reduzir-se o sentido da dignidade humana à defesa dos direitos pessoais tradicionais, esquecendo-a nos casos de direitos sociais, ou invocá-la para construir 'teoria do núcleo da personalidade' individual, ignorando-a quando se trate de direitos econômicos, sociais e culturais"."1 Daí decorre que a ordem econômica há de ter por fim assegurar a todos existência digna (art. 170), a ordem social visará a realização da justiça social (art. 193), a educação o desenvolvimento da pessoa e seu preparo para o exercício da cidadania (art. 205) etc., não como meros enunciados formais, mas como indicadores do conteúdo normativo eficaz da dignidade da pessoa humana. ${ }^{12}$

\section{Natureza da dignidade tutelada}

Para bem definir o objeto da tutela constitucional, há que se considerar que a palavra dignidade é empregada em diversos contextos com sentidos qualificados. Fala-se em dignidade espiritual, dignidade intelectual, dignidade social e dignidade moral. ${ }^{13}$ Quando Carlos Nino diz que o princípio da dignidade da pessoa é o "que prescreve que os homens devem ser tratados segundo suas decisões, intenções ou manifestações de consentimento", refere-se certamente àquelas várias acepções de dignidade, que se ligam a formas de comportamento. Mas a dignidade da pessoa humana, concebida pela Constituição como fundamento do Estado Democrático de Direito e, pois, como valor supremo da democracia, é de outra natureza.

11 Cf. Constituiçāo da República Portuguesa anotada, Coimbra, Coimbra Editora, 1984, p. 70.

12 Cf. nosso Curso de Direito Constitucional Positivo, 9a ed., São Paulo, Malheiros, 1984, p. 96.

13 Cf. René le Senne, Traité de Morale Générale, 5a ed., Paris, PUF, 1967, pp. 587 e 588. 
De fato, a palavra dignidade é empregada seja como uma forma de comportar-se seja como atributo intrínseco da pessoa humana; neste último caso, como um valor de todo ser racional, independentemente da forma como se comporte. ${ }^{14}$ É com esta segunda significação que a Constituição tutela a dignidade da pessoa humana como fundamento do Estado Democrático de Direito, de modo que nem mesmo um comportamento indigno priva à pessoa dos direitos fundamentais que lhe são inerentes, ressalvada a incidência de penalidades constitucionalmente autorizadas. ${ }^{15}$ Por isso, consoante lembra Jesús González Péres, é inconcebível afirmar - como fazia Santo Tomás de Aquino para justificar a pena de morte - que o homem ao delinqüir se aparta da ordem da razão, e portanto decai da dignidade humana e se rebaixa em certo modo à condição de bestas (S. Th. II-II, q. 64, a 2, ad. 3)". ${ }^{16}$

Porque a dignidade acompanha o homem até sua morte, por ser da essência da natureza humana, é que ela não admite discriminação alguma e não estará assegurada se o indivíduo é humilhado, discriminado, perseguido ou depreciado, ${ }^{17}$ pois, como declarou o Tribunal Constitucional da República Federal da Alemanha, "à norma da dignidade da pessoa humana subjaz a concepção da pessoa como um ser éticoespiritual que aspira a determinar-se e a desenvolver-se a si mesma em liberdade". ${ }^{8}$ Aliás, Kant já afirmava que a autonomia (liberdade) é o princípio da dignidade da natureza humana e de toda natureza racional, considerada por ele um valor incondicionado, incomparável, que traduz a palavra respeito, única que fornece a expressão conveniente da estima que um ser racional deve fazer dela. ${ }^{19}$

Não basta, porém, a liberdade formalmente reconhecida, pois a dignidade da pessoa humana, como fundamento do Estado Democrático de Direito, reclama condições mínimas de existência, existência digna conforme os ditames da justiça social como fim da ordem econômica. É de lembrar que constitui um desrespeito à dignidade da pessoa humana um sistema de profundas desigualdades, uma ordem econômica em que inumeráveis homens e mulheres são torturados pela fome, inúmeras crianças vivem na inanição, a ponto de milhares delas morrerem em tenra idade. ${ }^{20}$ "Não é concebível uma vida com dignidade entre a fome, a miséria e a incultura", pois, a "liberdade humana com frequiência se debilita quando o homem cai na extrema necessidade", pois, a "igualdade e dignidade da pessoa exigem que se chegue a uma situação social mais humana e mais justa. Resulta escandaloso o fato das excessivas desigualdades econômicas e sociais que se dão entre os membros ou os povos de

14 A propósito, cf. Fernando Garrido Falla, Comentarios a la Constitución, Madrid, Civitas, 1985, comentário ao art. 10,1, p. 187.

15 Cf. Fernando Garrido Falla. ob. cit. supra,k p. 187.

16 Ob. cit., p. 25.

17 Cf. Robert Alexy, Teoria de los Derechos Fundamentales, Madrid, Centro de Estudios Constitucionales, 1993, p. 345, trad. do alemāo por Ernesto Garzón Valdés; cf. também Jesús González Pérez, ob. cit., p. 25.

18 In Robert Alexy, ob. cit., p. 345.

19 Cf. ob. cit., p. 114.

20 Cf. Jesús González Pérez, ob. cit., pp. 62 e 63, citando a Encíclica Populorum Progressio, n. 45. 
uma mesma família humana. São contrários à justiça social, à eqüidade, à dignidade da pessoa humana e à paz social e internacional". ${ }^{21}$

\section{Conclusão}

Em conclusão, a dignidade pessoa humana constitui um valor que atrai a realização dos direitos fundamentais do homem, em todas as suas dimensões, e, como a democracia é o único regime político capaz de propiciar a efetividade desses direitos, o que significa dignificar o homem, é ela que se revela como o seu valor supremo, o valor que a dimensiona e humaniza. 